\title{
MEDIACIÓN OBLIGATORIA. ALGUNAS RAZONES PARA JUSTIFICAR SU INCORPORACIÓN
}

\author{
Macarena Vargas Pavez*
}

\begin{abstract}
RESUMEN
El colapso, a que poco andar se vieron sumidos los Tribunales de Familia, obligó al Ejecutivo a enviar un proyecto de ley que contiene un conjunto de medidas tendientes a descongestionar esta nueva judicatura. Entre ellas, se sustituye la voluntariedad de la mediación por la derivación obligatoria, en forma previa a la interposición de la demanda, para ciertas materias. Determinar los objetivos de política pública que subyacen a esta medida, su adecuación a los principios que animan la mediación y sus efectos a la luz de la experiencia de los tribunales de familia, son las temáticas que aborda el presente trabajo.
\end{abstract}

MEDIACIÓN - DERECHO DE FAMILIA - PROCESO DE FAMILIA

Mandatory mediation. Some reasons to justify its incorporation

Abstract

The collapse in which the Family Court fell into shortly after its beginning, forced the Government to send a bill that contains a set of measures that have the tendency to decongest this new judgeship. In the set of measures voluntarity of mediation is substituted by mandatory derivation, in a previous form of a lawsuit appeal for certain matters. This paper's objective is to appeal to determining public policy objectives that underlie this measure, its adaptation to the principles that encourage mediation and its effects in Family Court experience.

MEDIATION - FAMILY LAW - FAMILY PROCEDURE

* Abogada, Magíster en Gestión y Políticas Públicas, Profesora e investigadora en la Facultad de Derecho de la Universidad Diego Portales, Santiago de Chile, macarena.vargas@udp.cl. Artículo recibido el 22 de agosto de 2008 y aceptado para su publicación por el Comité Editorial el 24 de octubre de 2008. 


\section{INTRODUCCIÓN}

$\mathrm{L}$ as políticas públicas de justicia de estos últimos años se han abocado del desafío de modernizar el sistema de administración de justicia, no sólo por la vía de aumentar la capacidad de éste para resolver conflictos, sino que también haciéndose cargo del modo en que el sistema los resuelve.

Diversas iniciativas se encaminan en tal sentido. Una de ellas es la Reforma a la Justicia Familiar a través de la Ley No 19.968 de 2004 que crea los Tribunales de Familia, cuyo objetivo es "dotar a nuestro sistema de administración de justicia de órganos y procedimientos para hacer frente a un especial tipo de contencioso -el de naturaleza familiar- para el cual hoy nuestro ordenamiento carece de una respuesta específica". ${ }^{1}$

El modelo de adjudicación de derechos, hasta ahora predominante en nuestro ordenamiento jurídico, resulta especialmente inadecuado para resolver los conflictos familiares por la naturaleza sistémica de éstos y el tipo de relaciones que están en juego. Por ello, esta reforma perseguía, a través de la introducción de la mediación, proporcionar a las partes instancias para llegar a soluciones cooperativas donde se privilegie la participación directa de los involucrados, se mitiguen los niveles de confrontación y se mejoren los niveles de bienestar social.

Considero que el esfuerzo por propiciar un abordaje del contencioso familiar distinto que permita ofrecer respuestas nuevas y socialmente más adecuadas impone, desde una perspectiva de políticas públicas, interrogantes como las que siguen: ¿Qué acciones estatales habría que emprender para legitimar un mecanismo de estas características? ¿Cuáles son los incentivos adecuados para promover su utilización en la población? ¿Constituye la derivación obligatoria a mediación un aliciente eficaz para ello? A casi tres años de la puesta en marcha de los tribunales de familia, ¿cuál ha sido el resultado de la mediación voluntaria o facultativa?

Este trabajo pretende responder algunas de estas interrogantes y dar luces sobre una discusión necesaria, si no imprescindible, teniendo en vista el funcionamiento de los tribunales de familia, la subutilización de la mediación y la reforma de la Ley No 19.968 de Tribunales de Familia recientemente aprobada por el Congreso Nacional y próxima a promulgarse. ${ }^{2}$

Centraré mi atención específicamente en el análisis de las ventajas y desventajas de la mediación obligatoria versus la mediación voluntaria o facultativa, para luego revisar cuál de estas dos opciones se aviene mejor con los objetivos que se tuvieron a la vista en el diseño de la nueva judicatura familiar.

A mi juicio, existen fuertes razones para sostener que la mediación voluntaria, tal como está regulada en la actualidad en la Ley $\mathrm{N}^{\circ} 19.968$, no es desde una perspectiva de políticas públicas el camino más apropiado ni prácticamente el más eficiente para

${ }^{1}$ Mensaje del Presidente de la República al proyecto de ley que crea los Tribunales de Familia, Boletín $\mathrm{N}^{\circ}$ 2118-18. 5 de noviembre de 1997.

${ }^{2}$ Cámara de Diputados. Oficio N N $^{\circ} 517$ de 12 de junio de 2008. A la fecha de elaboración de este artículo, el texto aprobado era objeto de estudio por parte del Tribunal Constitucional. 
impulsar esta nueva forma de abordar el conflicto familiar, especialmente en atención a la evidencia empírica que muestra escasos índices de derivación judicial.

Por el contrario, estimo que en la primera etapa de divulgación y legitimación social de la mediación -y aun a riesgo de aparecer en contradicción con los postulados básicos de este proceso- es necesario vincularla al sistema judicial y establecer la comparecencia obligatoria a programas de mediación anexos a los tribunales. Considero además que su inserción cultural exige que estos programas sean profusa y adecuadamente difundidos a la comunidad, sean de fácil acceso y de costo cero para las familias. Por último, estimo que el Estado debe ejercer un fuerte control en la calidad de la formación de los mediadores familiares y en los servicios que éstos prestan. Sólo así se podrá cumplir con el cometido de la política pública de justicia delineado: ampliar y mejorar la oferta de tutela jurisdiccional.

\section{LA MEDiaCión FAMILIAR COMO OBJETIVO DE POLÍ́tiCA DE JUSTICIA}

La mediación familiar ha sido definida de múltiples maneras. Gran parte de los autores concuerdan en su carácter autocompositivo, en el rol facilitador del mediador y en la búsqueda de satisfacción de los intereses y necesidades de las partes que permite, de ser necesario, la continuidad de las relaciones de los involucrados. ${ }^{3}$ Su estudio se ha situado principalmente en el marco de procesos de ruptura de pareja, separación y divorcio ${ }^{4}$, sin perjuicio de que ella puede cubrir un ámbito de intervención mayor, como, por ejemplo, los conflictos familiares intergeneracionales. ${ }^{5}$

La Ley $\mathrm{N}^{\circ} 19.968$ de Tribunales de Familia en términos gruesos adhiere a esa tendencia y la define como "aquel sistema de resolución de conflictos en el que un tercero imparcial, sin poder decisorio, llamado mediador, ayuda a las partes a buscar por sí mismas una solución al conflicto y sus efectos, mediante acuerdos". ${ }^{6}$

La incorporación de los mecanismos alternativos dentro de los procesos de reforma de los sistemas judiciales puede tener variadas motivaciones. A juicio de Juan Enrique Vargas, existen tres grandes justificaciones para el establecimiento de estos métodos: (a) aumentar el acceso a sistemas de resolución de conflictos para aquellos casos que de otra

${ }^{3}$ Cárdenas, E., La mediación en conflictos familiares, Editorial Lumen/Humanitas, Buenos Aires, 1998, p. 64; Suares, M., Mediando en sistemas familiares, Editorial Paidós, Buenos Aires, 2002, p. 244; Haynes, J., Fundamentos de la Mediación Familiar, Gaia Ediciones, Barcelona, 1993, p. 17; Moore, C., El proceso de mediación. Métodos prácticos para la resolución de conflictos, Editorial Granica, Buenos Aires, 1995, p. 44.

${ }^{4}$ Singer, L., Resolución de conflictos. Técnicas de actuación en los ámbitos empresarial, familiar y legal. Editorial Paidós, Barcelona, 1996, p. 55; Bernal, T., La mediación: una solución a los conflictos de ruptura de pareja, Ed. Colex, Madrid, 1998, p. 98.

${ }^{5}$ Six, J. F., Dinámica de la mediación, Editorial Paidós, Barcelona, 1997, pp. 52-54. Correa, P., "Los niños en la mediación familiar. Comentarios al artículo de Macarena Vargas”, en Revista de Derechos del Niño, Facultad de Derecho Universidad Diego Portales, num. 1, 2002, p. 168.

${ }^{6}$ Artículo 103. Ley No 19.968 de Tribunales de Familia publicada en el Diario Oficial el 30 de agosto de 2004 . 
manera no tendrían respuesta, principalmente aquellos que afectan a los sectores más pobres; (b) descargar de trabajo a los tribunales haciendo más eficiente su gestión y (c) mejorar la calidad de soluciones a través de una mayor participación de las partes. ${ }^{7}$

Esta última justificación es la que Carlos Peña entrega para sostener que los mecanismos alternativos de resolución de conflictos "poseen importantes ventajas para una política de justicia que desee ser eficiente y socialmente adecuada". ${ }^{8}$ Sobre la base de datos empíricos, argumenta que el creciente aumento de los litigios y la mayor heterogeneidad en la composición de éstos imponen al Estado el deber de brindar a la ciudadanía una oferta heterogénea de protección y tutela jurisdiccional. A su juicio, los mecanismos alternativos ofrecen mayores niveles de bienestar social en función de los menores costos que involucran y de la ampliación de acceso que provocan. ${ }^{9}$

En el caso de los conflictos familiares estas razones adquieren mayor relevancia debido a los singulares rasgos que este tipo de problemas poseen. En primer lugar, los mecanismos alternativos son especialmente adecuados para abordar los conflictos de familia por la naturaleza sistémica y multidimensional de éstos. ${ }^{10} \mathrm{El}$ sistema familiar está compuesto por diversos subsistemas - parental, conyugal, fraternal- que generan un abanico de relaciones de interdependencia entre sus miembros. De allí que la ruptura de pareja que pone fin al subsistema conyugal no debiera afectar las relaciones entre padres e hijos -subsistema parental-, aunque en la práctica esto ocurre con no poca frecuencia. Las soluciones del tipo suma cero, en lo que uno gana el otro lo pierde, propias del sistema de adjudicación de derechos no contribuyen al ejercicio compartido de los roles parentales. Por el contrario, la adjudicación que supone la definición de vencedores y vencidos no hace sino ahondar las diferencias y desacuerdos al interior de las familias. Por ello se considera que este tipo de problemáticas exigen dejar atrás un "criterio individualista y lineal propio de nuestro derecho" 11 y dar paso a un criterio integrador y sistémico, que permita la mantención de las relaciones parento-filiales más allá de la ruptura de pareja.

En segundo lugar, este tipo de conflictos expande sus efectos a otras personas. En caso de haberlos, impacta fuertemente a niños, niñas y adolescentes, los que se verán afectados por las decisiones de sus padres. La Convención de Derechos del Niño ratificada por Chile en 1990, ha dado pie una serie de modificaciones en el campo legal que incluyen, entre otras, normas relativas a la consideración del interés superior del niño

7 Vargas, J. E., "Problemas de los sistemas alternos de resolución de conflictos como alternativa de política pública en el sector judicial”, en Revista Sistemas Judiciales, Centro de Estudios de Justicia de las Américas (CEJA), núm. 2, 2002, p. 13 a 17. Este autor afirma que la falta de diálogo entre las distintas motivaciones explica que estos mecanismos, pese a la adhesión que provocan en distintos sectores sociales, no logren consolidarse dentro de las reformas judiciales de Latinoamérica y posean un carácter marginal o experimental.

${ }^{8}$ Peña, C., "Los sistemas alternativos de resolución de conflictos", en Revista de Estudios Sociales, núm. 88, Corporación de Promoción Universitaria (CPU), Santiago, 1996, p. 91.

9 Ibid.

${ }^{10}$ Mensaje del Presidente de la República al proyecto de ley que crea los Tribunales de Familia, Boletín $\mathrm{N}^{\circ}$ 2118-18. Noviembre de 1997.

${ }^{11}$ Turner, S., "Los Tribunales de Familia”, en Revista Ius et Praxis, vol. 8, No 2, Talca, 2002, p. 418. 
como un elemento primordial a la hora de decidir sobre temas que puedan afectar sus derechos e intereses. ${ }^{12}$ La doctrina nacional ha sostenido que este interés se encuentra íntimamente ligado al concepto de autonomía progresiva y al derecho de los niños, niñas y adolescentes a ser escuchados en todos los asuntos judiciales y administrativos cuyas decisiones puedan impactar su vida futura. ${ }^{13}$ El contexto judicial no suele ser amigable para adultos, menos aún para los niños, de ahí que existan serias dudas acerca si el sistema es capaz de asumir esta tarea ofreciendo condiciones mínimas de protección y contención emocional de los niños.

En tercer lugar, el carácter dinámico y evolutivo del ciclo vital familiar exige hacerse cargo del grado de perdurabilidad de las soluciones de los conflictos de familia. Cualquiera sea la biografía de una familia, a lo largo de los años ella atravesará por diversas etapas marcadas por el desarrollo de sus miembros. En la medida que los niños crecen y los adultos envejecen se generan nuevas situaciones vitales y surgen distintas necesidades que satisfacer. De ahí que las respuestas a los conflictos familiares no pueden ser ni estándares ni estáticas, deben permitir su revaluación y eventual ajuste de acuerdo a las circunstancias. Si bien, a través de la noción de cosa juzgada formal ${ }^{14}$, la doctrina se hace cargo del carácter dinámico del conflicto familiar, la respuesta judicial supone volver al sistema de adjudicación de derechos cada vez que una nueva situación de cambio genere desacuerdos en la familia. Por lo general, las sentencias judiciales buscan resolver un conflicto puntual y no contemplan un plan de acción destinado a prevenir y/o enfrentar futuras controversias.

Consideraciones similares se contemplan en la Recomendación $\mathrm{N}^{\circ} \mathrm{R}$ (98)1 del Comité de Ministros del Consejo de Europa sobre Mediación Familiar. En ella se insta a los Estados Miembros a promover y adoptar programas de mediación familiar en atención a que este tipo de conflictos involucra a personas que por definición tendrán relaciones interdependientes y continuas en el tiempo, porque se trata además de conflictos que se desenvuelven en un contexto emocional estresante que los incrementa y porque la separación y el divorcio impactan a todos los miembros de la familia, en especial a los niños. $^{15}$

${ }^{12}$ Artículo 16 de la Ley No 19.968 de Tribunales de Familia publicada en el Diario Oficial el 30 de agosto de 2004. En este mismo sentido, otra manifestación de ello es la incorporación de la figura del curador ad litem (artículo 19).

${ }^{13}$ Couso, J., "El niño como sujeto de derechos y la nueva Justicia de Familia. Interés Superior del Niño, Autonomía progresiva y derecho a ser oído", en Academia Judicial de Chile. Derecho de Familia e Infancia, Santiago, 2005, pp. 7-20; Cillero, M., "El interés superior del niño en el marco de la Convención Internacional de los Derechos del Niño”, en García, E. (compilador), en Infancia, Ley y Democracia en América Latina. Temis, Bogotá, 1999, pp. 83-84; Couso, J., “Más acá del Interés Superior del Niño”, en García, E. (compilador), Infancia, Ley y Democracia en América Latina. La cuestión de la responsabilidad penal de los adolescentes, Ediciones del Signo, Buenos Aires, 2004, p. 46.

${ }^{14}$ Colombo, J., La jurisdicción, el acto jurídico procesal y la cosa juzgada en el derecho chileno, Editorial Jurídica de Chile, Santiago, 1980, p. 125; Pereira, H., La cosa juzgada en el proceso civil, Editorial Jurídica ConoSur Ltda., Santiago, 1997, p. 57.

${ }^{15}$ Recomendación N ${ }^{\circ}$ R (98)1 del Comité del Ministros de los Estados Miembros sobre Mediación Familiar (21 de enero de 1998). www.coe.int. Visitada el 9 de agosto de 2006. 
El objetivo de ampliar y mejorar la oferta de respuestas al conflicto familiar encuentra también sus antecedentes en experiencias comparadas que avalan el éxito de la incorporación de los denominados mecanismos "ADR" (Alternative Dispute Resolution), por ejemplo, a través de los programas Multi-Door Courthouse que se ejecutan desde mediados de los años ochenta en varios estados de Estados Unidos. ${ }^{16}$ Los programas Multi-Door Courthouse persiguen precisamente ofrecer a las personas varias posibles "puertas de entrada” al sistema de administración de justicia, desde la negociación hasta el litigio, pasando por la mediación, el arbitraje, evaluación del caso, mini-trials y otras fórmulas híbridas que combinan unos y otros mecanismos.

Este modelo de intervención fue propuesto en 1976 por el profesor F. Sander en la Conferencia Roscoe E. Pound que tuvo como objetivo analizar las causas de insatisfacción de la población con la administración de justicia. Sander sostuvo que una vía para reducir la recarga judicial era explorar formas alternativas para resolver los conflictos en los tribunales y propuso establecer un sistema de asignación de ciertos casos a ciertos procesos de ADR (o a una secuencia de ellos), después de un proceso de screening en un centro de resolución de disputas. ${ }^{17}$

Estos y otros elementos forman parte del contexto en el cual el Ejecutivo incorpora la mediación en el proyecto de ley que crea los Tribunales de Familia, despachado al Congreso Nacional en 1997. En paralelo -y debido a la escasez de información y de evidencia empírica a nivel nacional-, impulsa un proyecto piloto destinado a testear la factibilidad de este mecanismo en el contexto nacional, evaluar las condiciones de aplicación y sus posibles resultados. ${ }^{18}$

En efecto, y de acuerdo a lo señalado en el Mensaje Presidencial del proyecto de ley que crea los Tribunales de Familia, la mediación se inserta dentro de la reforma de la justicia de familia con un claro objetivo de política pública: ampliar y mejorar la oferta de tutela jurisdiccional, en consideración de las particulares características del conflicto familiar.

Si bien en el Mensaje no hay mención expresa que justifique su inserción por razones de eficiencia y gestión de los tribunales de familia, este elemento se tuvo en consideración durante el proceso de diseño de la ley como un objetivo secundario, lo que es posible

\footnotetext{
${ }^{16}$ National Center of State Courts and State Justice Institute, National Symposium on Court-connected Dispute Resolution Research. A Report on Current Research Findings-Implications for Courts and Futures Research Needs, 1994, pp. 93-101. Véase también: Davis, W., "Diseño de sistemas para resolver conflictos: La experiencia con multipuertas en Estados Unidos” en Gottheil, J. y Schiffrin, A., Mediación. Una transformación en la cultura, Editorial Paidós, Buenos Aires, 1996, pp. 191-214.

${ }^{17}$ Sander, F., "Varieties of Dispute Processing. National Conference on the Dissatisfaction with de Administration of Justice", en Federal Rules Decisions, West Publishing CO, vol. 70, num. 1, Minnesota, 1976. La propuesta del profesor Sander es ampliamente reconocida como uno de los hitos iniciales del movimiento de los ARD en Estados Unidos. Para mayor información: Barona, S., La solución extrajudicial de conflictos. ADR y Derecho Procesal. Tirant Lo Blanch. Valencia; 1999, p. 57. Singer, L., op. cit., p. 19; Davis, W., op. cit., p. 199.

18 Vargas, M. (ed.), Mediación Familiar. Sistematización de una experiencia, Ministerio de Justicia de Chile, Santiago, 2000, p. 80.
} 
desprender de los documentos de trabajo de la comisión redactora del proyecto y de los estudios de estimación de la demanda y de costos realizados en aquel período.

El proyecto de ley original preveía la mediación como un proceso alternativo y complementario al judicial y revestía distintas modalidades considerando la diversidad de asuntos de que conoce la justicia familiar. Se estableció un sistema mixto, en virtud de cual los asuntos de alimentos, cuidado personal y régimen comunicacional serían de mediación obligatoria. El resto de las materias, salvo las prohibidas, serían de mediación facultativa o voluntaria. Se prohibió la mediación para asuntos relativos al estado civil, maltrato y abuso infantil, la adopción, entre otras. ${ }^{19}$

De acuerdo al proyecto de ley original de Tribunales de Familia tanto la mediación obligatoria como la voluntaria se insertaban dentro del marco de un proceso judicial. La primera operaría por un mandato legal, en virtud del cual el tribunal debe ordenar a las partes a concurrir a una sesión inicial de mediación para recibir información completa sobre el proceso y ejercer luego una opción plenamente informada. Si después de escuchar al mediador ambas partes aceptan participar, se da comienzo el proceso, si por el contrario, una o ambas no adhieren a la propuesta, éste nunca comenzó. La "obligatoriedad" entonces consistía solo en concurrir a una primera sesión de carácter informativo a cargo de un profesional capaz de explicar con detalle el proceso y resolver todas las dudas que surjan. Por su parte, la mediación voluntaria o facultativa operaría, de acuerdo a la ley, previa sugerencia del juez y con la anuencia de ambas partes. No obstante lo anterior, las partes siempre tendrían la posibilidad de acceder a los servicios de un mediador, si así lo acordaren, en forma extrajudicial.

El Ejecutivo optó por establecer la mediación obligatoria para las materias antes mencionadas -alimentos, cuidado personal y régimen comunicacional-en consideración a tres elementos centrales. Por una parte, este tipo asuntos son de aquellos que típicamente surgen como consecuencia de la ruptura de la pareja, sea ésta conyugal o no, cuestión que se pudo verificar en Chile a través de la experiencia piloto del Ministerio de Justicia. ${ }^{20}$ Por otra parte, a la sazón estos asuntos constituían el $70 \%$ de las causas civiles ingresadas a los tribunales de menores de la época. ${ }^{21}$ Finalmente, se consideró que dado que en Chile no había (ni hay aún) una cultura instalada que reconozca el valor de las soluciones cooperativas, en general, y de la mediación, en particular, desarrollada sobre el objetivo y valor de la mediación era necesario establecerla como una etapa previa y obligatoria al juicio con el fin de darla a conocer a la ciudadanía.

El proyecto de ley de 1997 contemplaba además que tanto la mediación obligatoria como voluntaria sería gratuita, sin importar el nivel socioeconómico de las partes. El Estado a través de un sistema de licitaciones proveería de la adecuada oferta de servicios de mediación en todo Chile.

${ }^{19}$ Mensaje del Presidente de la República, op. cit.

${ }^{20}$ Vargas, M. (ed.), op. cit., p. 45.

21 Información proveniente de registros estadísticos de la Corporación Administrativa del Poder Judicial. 1997. 
En este marco, se preveía - de acuerdo a las proyecciones del Ejecutivo- que la mediación sería accesible a un alto número de familias, las que tendrían la posibilidad de resolver sus conflictos en forma cooperativa y, de paso, se descargaría a los tribunales de familia de al menos un $25 \%$ de los casos ingresados, cumpliendo con los objetivos planteados. ${ }^{22}$

La Cámara de Diputados aprobó el texto original enviado por el Ejecutivo; ${ }^{23}$ sin embargo, éste fue sustancialmente modificado por la Comisión de Constitución, Legislación, Justicia y Reglamento del Senado. Sin mayor discusión, los senadores decidieron otorgar el carácter de voluntario al nuevo proceso -solo con la declaración de voluntad expresa de ambas partes se podría derivar a mediación-y establecer un sistema mixto de costos - la mediación sería de cargo de las partes, a menos que contaran con un informe favorable que las eximiera del pago. ${ }^{24}$

Estimo que el texto aprobado burocratizó el acceso a la mediación en forma excesiva, generando un complejo sistema de desincentivos que rompen con los objetivos de política pública que subyacen a su incorporación. La evidencia empírica se encargó de demostrar que esta regulación atentó contra la socialización y aplicación de este nuevo mecanismo. De acuerdo a los datos del Ministerio de Justicia, durante el año 2006 se derivó desde los tribunales de familia un 2,9\%, advirtiéndose un leve aumento en el $2007(5,7 \%),{ }^{25}$ lo cual paradójicamente se produce en un escenario de alta congestión y recarga de trabajo. ${ }^{26}$

Varias razones pueden explicar este fenómeno: una escasa -y a ratos confusa- difusión a los potenciales usuarios de los servicios, la puesta en marcha tardía del sistema licitado (cinco meses después de la entrada en vigencia de los tribunales de familia) y un engorroso sistema de derivación de casos, entre otros. Sin embargo, estimo que el factor preponderante es el "factor judicial": nos encontramos frente a la resistencia de un Poder Judicial que no conoce la mediación y sospecha de ella.

${ }^{22}$ Informe de la Subcomisión sobre Mediación de la Comisión de reforma de la Ley de Tribunales de Familia, documento inédito, Ministerio de Justicia, Santiago, 2006.

${ }^{23}$ Informe de las Comisiones Unidas de Constitución, Legislación y Justicia y de Familia recaído en el Proyecto de Ley que crea los Juzgados de Familia. Boletín No 2118-18.

${ }^{24}$ Segundo Informe de la Comisión de Constitución, Legislación y Justicia del Senado recaído en el Proyecto de Ley que crea los Juzgados de Familia. Boletín No 2.118-18 Valparaíso, 9 de julio de 2003.

${ }^{25}$ Facultad de Derecho de la Universidad Diego Portales y Centro de Estudio de Justicia de las Américas (CEJA). Informe Final Estudio "Diseño de un Modelo de Licitación Pública de Servicios de Mediación. Santiago, 2008, p. 14.

${ }^{26}$ Durante el año 2006 ingresaron a los tribunales de familia (especializados) y a los juzgados de letras con competencia en materia de familia un total de 449.297 causas, en circunstancias que las estimaciones del Ministerio de Justicia preveían un ingreso de aproximadamente 185.000 causas al año. Para mayor información véase: Pontificia Universidad Católica de Valparaíso, Centro de Estudios de Asistencia Legislativa (CEAL), Informe final Estudio "Impacto de la reforma a la Ley $N^{\circ} 19.968$ en la demanda de ingresos de los Tribunales de Familia y el Sistema Nacional de Mediación”, vol. 1, Valparaíso, 2007. 


\section{La mediación obligatoria. Alcances, límites y resultados}

Hay consenso en la literatura especializada de que la participación libre y voluntaria de las personas es uno de los principios rectores del proceso de mediación. Nadie puede ser compelido a participar en una mediación, ni menos a llegar a acuerdos.

La voluntariedad no solo se agota en la decisión de acceder al proceso, sino que exige asumir un rol protagónico en su desarrollo. Impone a las partes disponer de un ánimo colaborativo, adoptar una actitud activa en la búsqueda de alternativas de solución y tener apertura y flexibilidad para escuchar y valorar las alternativas propuestas por el otro. Incluso hay quienes sostienen que estas exigencias pueden ser consideradas como verdaderos deberes éticos de las partes dentro de un proceso de mediación. ${ }^{27}$

La voluntariedad tiene dos dimensiones. La primera comprende la etapa inicial del proceso -cuando la persona toma la decisión de acogerse a él- y la segunda comprende la facultad de retirarse de éste en cualquier momento sin necesidad de justificar los motivos. Basta la expresión de la voluntad de una de las partes en orden a no continuar para que el mediador deba poner término al proceso.

Marinés Suares sostiene que la participación voluntaria es un elemento de la esencia y atribuye el éxito de este proceso -expresado en el mayor grado de satisfacción y cumplimiento con los acuerdos en comparación con una sentencia judicial- precisamente porque las partes que edificaron el acuerdo concurrieron libremente a la mediación. ${ }^{28}$

Siguiendo esta línea, se ha sostenido que en la medida que las personas participan directamente en la construcción de las soluciones hay un mayor nivel de acuerdos, de satisfacción y de cumplimiento. Una investigación acerca de los programas anexos a tribunales en los estados de Washington, Nueva Jersey y Massachusetts arrojó interesantes conclusiones sobre su aplicación de éstos y resultados. ${ }^{29}$ El $90 \%$ de los usuarios dijo haber quedado completa o parcialmente satisfecho con el programa, mientras que un $92 \%$ señaló que volvería usarlo de nuevo en caso de requerirlo. En cuanto al nivel de acuerdo alcanzado, en el caso del programa de Washington D.C., del total de casos mediados un $87 \%$ terminó con un acuerdo; en el programa de Nueva Jersey un $55 \%$ de los casos y en Massachusetts, un $63 \%$ concluyó de esta forma. Este estudio no contiene datos sobre niveles de cumplimiento.

En el caso chileno, la evidencia empírica muestra un alto nivel de satisfacción con el proceso de mediación (93\% entre aquellos que arribaron a acuerdos y un $65 \%$ entre los que no llegaron a acuerdo alguno), con niveles de acuerdo por sobre el $54 \%$, pero con índices de cumplimiento por bajo del $50 \% .{ }^{30}$ Un estudio encargado por el Ministerio de

${ }^{27}$ Gómez, P., "Propuestas y reflexiones éticas acerca del ejercicio de la mediación en Chile como forma de resolución no adversarial de los conflictos", en Revista de Derecho de la Universidad Católica de Valparaíso, Valparaíso, 1999, p. 374.

28 Suares, M., op. cit., p. 31.

${ }^{29}$ National Center for State Courts/ State Justice Institute, op. cit., pp. 97-105.

30 Alliende, L. y otros, El proceso de mediación, Editorial Jurídica de Chile, Santiago, 2002, pp. 113114; Vargas, M. (ed.), op. cit., p. 83. 
Justicia en el 2006 sobre calidad de los servicios licitados de mediación familiar muestra que los usuarios califican positivamente la metodología de trabajo empleada (nota 6.2 a 6.3) y el desempeño del mediador (nota 6.3 a 6.4$).{ }^{31}$

Ahora bien, si uno de los principios fundantes de la mediación es la participación voluntaria de los involucrados en el conflicto, entonces la expresión "mediación obligatoria” no parece del todo feliz. Aparentemente lleva implícita una contradicción: ¿cómo puede obligarse a una persona a participar en la mediación si uno de los pilares básicos de este proceso es precisamente la voluntariedad? Pese a ello, es una expresión habitual en el estudio y práctica de los ADR, la que sin embargo se ha matizado con expresiones como "comparecencia obligatoria a mediación" 32 o "mediación involuntaria".33

El estudio de la obligatoriedad/voluntariedad en la mediación impone interrogantes como las que siguen: ¿Cómo pueden llegar las partes a la mediación? ¿Cuándo nos encontramos frente a una mediación obligatoria y cuándo frente a una voluntaria o facultativa? ¿En qué se distingue una de otra? ¿Cómo impactan dichas diferencias en los niveles de acuerdos y en los índices de satisfacción de los usuarios? ¿La mediación obligatoria tiene mayor impacto en la descongestión de los tribunales que la voluntaria? ¿La mediación obligatoria introduce a las partes a un proceso que más tarde podrían elegir voluntariamente? ¿Pueden los tribunales (o la ley) obligar a las partes soportar los costos de tiempo que impone la mediación obligatoria? ¿Qué sucede si se comparan los índices de satisfacción de la mediación obligatoria con los índices de satisfacción de las sentencias judiciales?

En un estudio sobre la eficacia de la mediación realizado en 1997, Brett, Barsness y Goldberg distinguen entre mediación voluntaria y mediación involuntaria. En el primer grupo -mediación voluntaria o facultativa- se encuentran aquellos casos que llegan a mediación por el acuerdo de las partes, por la solicitud de una de ellas o por el consejo de una tercera persona. En el segundo grupo -mediación involuntaria- se encuentran aquellos que acceden al proceso porque han sido requeridos por una cláusula contractual, por orden del tribunal o por la sugerencia del juez. ${ }^{34}$

Por su parte, Moore señala que existen cuatro grandes vías de ingreso a la mediación: (a) por iniciativa directa de las partes, sea de una de ellas o ambas de común acuerdo; (b) por remisión de participantes secundarios, entendiendo por ellos quienes no siendo partes directas están interesadas en la resolución de conflictos, como por ejemplo, familiares, amigos, vecinos o cualquier otra persona a quien pueda beneficiar la solución del

${ }^{31}$ Facultad de Ciencias Económicas y Administrativas (FACEA), Universidad de Concepción, Estudio sobre la calidad de los servicios licitados de mediación del Ministerio de Justicia, Concepción, 2006. http://www. minjusticia.cl/Nueva\%20pagina\%20mediacion/noticias/Resultados\%20Satisfaccion\%20de \%20la\%20Calidad. pdf. Página visitada el 7 de julio de 2008.

32 State Justice Institute (SJI). Normas recomendadas para programas de mediación anexos a los tribunales. Traducción al castellano realizada por la Fundación Libra de Argentina. Buenos Aires, 1993, p. 42.

33 Brett, J., Barsness, Z. y Goldberg, S., "La eficacia de la mediación. Un análisis independiente de casos gestionados por cuatro importantes proveedores de servicio”, en Burs, M.I. (coord.), Suplemento de Resolución de Conflictos (R.C.), La Ley, Buenos Aires, 1997, pp. 1-9.

${ }^{34}$ Ibíd. 
conflicto; (c) por iniciativa directa del propio mediador y (d) por designación realizada por una autoridad. ${ }^{35}$ En este último caso, Moore no distingue si se trata de un juez u otro tipo de autoridad estatal y si la designación corresponde a una orden o una sugerencia de ésta aceptada por las partes, pero claramente las tres primeras parecen aludir a la mediación voluntaria de Brett, Barsness y Goldberg, mientras que la última puede clasificarse como de mediación involuntaria.

Desde esta perspectiva, las diferencias entre la mediación obligatoria y voluntaria en nuestro país parecen diluirse. A la luz de la tipología de Brett, Barsness y Goldberg, la mediación situada en el contexto judicial siempre será mediación obligatoria, sea que opere por mandato legal, por orden o sugerencia del juez. Como se aprecia, el elemento determinante está dado por la intervención judicial, la voluntad de las partes aparece entonces "mediada" por la autoridad.

De lo anterior se sigue que la mediación voluntaria -como se ha entendido en Chile- no sería sino una modalidad de mediación obligatoria. La mediación facultativa ciento por ciento pura sería aquella que se desarrolla fuera del sistema judicial y que nace por iniciativa propia de una o de ambas partes o por recomendación o derivación de un tercero significativo para ellas. Esto es lo que en Chile los mediadores practicantes han denominado mediación por "demanda espontánea".

Esta concepción se corrobora con la opinión de los usuarios de mediación familiar, según dan cuenta los resultados de un estudio sobre "Mediación Familiar y Género" realizado por la Facultad de Derecho de la Universidad Diego Portales. En el marco de esta investigación se entrevistó a usuarios derivados a mediación por los tribunales de familia previa sugerencia del juez (mediación voluntaria de acuerdo a la Ley 19.968) y otros que llegaron al proceso por iniciativa propia o por derivación de un tercero (mediación por demanda espontánea). Se advirtieron diferencias significativas entre unos y otros, tanto en relación a la información que tienen sobre mediación como en la predisposición con que acceden al proceso.

La percepción de quienes fueron derivados por el tribunal está muy lejos de la idea de la elección libre y voluntaria de la mediación. Por el contrario, los entrevistados relatan que aceptan la sugerencia del juez con una alta cuota de malestar, pues consideran que se trata de un trámite más, es decir, una obligación que deben cumplir para conseguir su cometido. Dado que en la mayoría de los entrevistados, hasta antes de la derivación judicial, desconocía la existencia de la mediación, concurren además con sentimientos de temor e incertidumbre, razón por la cual se declaran, en un principio, abiertamente reacios a participar. Para este estudio la muestra exigía que los usuarios hubiesen participado en un proceso de mediación y que éste hubiese finalizado con un acuerdo, por tanto no es posible medir el impacto de la voluntariedad/obligatoriedad en términos de los resultados del proceso. Sin embargo, esta muestra permite colegir que a pesar de la reticencia inicial los entrevistados que accedieron a participar en un proceso de mediación se mantuvieron en él, en circunstancias que podrían haberse retirado. Por otra parte,

35 Moore, C., op. cit., pp. 89-97. 
todos señalaron valorar positivamente el proceso, tanto que varios lo recomendarían a otros y volverían a utilizarlo. ${ }^{36}$

Así las cosas, estimo que no habría más que asumir que no es posible la mediación voluntaria en sede judicial y que cualquier tipo de mediación anexa a los tribunales es una modalidad de mediación obligatoria. En otras palabras, debemos abandonar la idea de que en sede judicial la mediación obligatoria es más perniciosa que la voluntaria o que vulnera los principios rectores del proceso. En ese escenario, no es más que una falsa dicotomía.

Pese a que las diferencias entre una y otra se diluyen y la búsqueda de argumentos a favor de la mediación obligatoria parece innecesaria, estimo igualmente útil conocer los beneficios y costos que se atribuyen a la obligatoriedad de la mediación y las recomendaciones de organismos especializados sobre la materia.

La mediación obligatoria o involuntaria presenta ventajas y desventajas. Desde el punto de vista de las ventajas, se sostiene que a través de la mediación obligatoria accede un volumen mayor de casos que por la vía de la voluntaria, lo que permitiría una reducción de costos de los programas y servicios de mediación (economías de escala) y una mejor asignación de los recursos del sistema de administración de justicia tornando más eficiente su gestión. Por otra parte, la mediación obligatoria podría significar a largo plazo un aumento de la utilización voluntaria de este mecanismo, dado que las partes podrán conocer y vivenciar un proceso de resolución de conflictos que, probablemente, de otro modo no hubieran intentado.

No obstante y homologando algunos de los argumentos que se han dado a favor del arbitraje obligatorio, puede decirse, como contrapartida, que la mediación involuntaria supone romper con una larga lista de barreras psicológicas de las partes que la mediación obligatoria resuelve sin problemas. Por ejemplo, si una de ellas sugiere la mediación, la otra puede sospechar que su propuesta busca obtener alguna ventaja posterior, como por ejemplo, obtener algún grado de información y/o intentar demorar el proceso. Otras barreras incluyen la ignorancia y la desinformación, la inercia (es mejor hacer las cosas como siempre se han hecho), el temor a lo desconocido y el temor a perder el control (como si esto último realmente fuera posible en un proceso judicial). ${ }^{37}$

En relación a las desventajas se ha señalado que la comparecencia obligatoria podría significar "arriesgarse a forzar a las partes a participar en un proceso que por una razón u otra, puede ser inapropiado”. 38 También puede provocar la generación y mantención de programas de mediación de baja calidad y poner obstáculos a las partes en la búsqueda de solución de sus conflictos. ${ }^{39}$

${ }^{36}$ Vargas, M., Casas, L., Azócar, M. J., Mediación Familiar y Género, Cuaderno de Análisis Jurídico, núm. 18, Serie Publicaciones Especiales, Facultad de Derecho, Universidad Diego Portales, Santiago, 2008, pp. 37-38.

${ }^{37}$ Brazil, W. y Wilson, W., “The arguments for and against mandatory arbitration”, en FJC Directions. Federal Judicial Center, $\mathrm{N}^{\circ} 7$, Washington. 1999, pp. 14-17.

38 op. cit., $\mathrm{N}^{\circ}$ 34. State Justice Institute. Normas Recomendadas.

${ }^{39}$ Este último argumento se ha planteado en la discusión nacional y se ha sostenido que la derivación obligatoria a mediación podría llegar a constituir si no una denegación de justicia al menos una forma de retardo de la respuesta jurisdiccional. 
En función de este análisis, el Comité de Políticas Públicas de la Society of Proffessionals in Dispute Resolution (SPIDR) de EE.UU. considera que la participación obligatoria en programas de mediación puede resultar apropiada, "pero sólo cuando el mandato tenga mayores probabilidades de servir a los intereses de las partes, del sistema judicial y del público, que la comparecencia voluntaria”. 40

Siguiendo esta línea, The State Justice Institute (SJI) del mismo país sugiere analizar cuidadosamente el punto y en el evento de optar por este camino establecer serios mecanismos de control para su aplicación. Las Normas Recomendadas para Programas de Mediación Anexo a Tribunales de esta institución sugieren que los programas de mediación obligatoria debieran operar siempre y cuando se pueda garantizar que:

a) Los costos de la mediación sean cubiertos por el Estado.

b) No existan coerciones para llegar a acuerdos.

c) Los mediadores y los programas de mediación sean: (i) de alta calidad, (ii) de fácil acceso, (iii) permitan la participación de las partes, (iv) permitan la participación de los abogados, cuando así lo deseen las partes y (v) brinden información clara y completa sobre los procesos y procedimientos precisos que se requieren. ${ }^{41}$

Además se recomienda que al momento de tomar la decisión tener en consideración ciertos aspectos importantes relativos al conflicto: costos monetarios y emocionales para las partes, el interés de las partes de alcanzar resultados acordes a sus necesidades, los intereses de las personas que no son partes, pero cuyas vidas pueden verse afectadas, la importancia de la confianza pública en el sistema de justicia, entre otras. ${ }^{42}$

Por su parte, y en relación directa con la mediación familiar, la Recomendación No R (98)1 del Comité de Ministros del Consejo de Europa establece que la mediación, en principio, no debe ser obligatoria, sin perjuicio de lo cual los Estados Miembros son libres de organizar y ofrecer la mediación como ellos estimen conveniente. No obstante, con independencia de cómo estos programas se organicen, se sugiere a los Estados Miembros contemplar mecanismos apropiados para asegurar la existencia de procedimientos de selección, capacitación y calificación de los mediadores y fijar estándares para el trabajo de éstos. 43

Existe escasa evidencia empírica acerca sobre las diferencias entre la mediación obligatoria y la voluntaria y el impacto de ellas en el sistema de administración de justicia y en los usuarios. Tuve acceso a revisar bibliografía relativa a dos estudios realizados en

${ }^{40}$ Report $\mathrm{N}^{\circ} 1$ of the Law and Public Policy Committee of the Society of Professionals in Dispute Resolution (SPIDR), "Mandated participation and settlement coercion: dispute resolution as it relates to the courts”, en Nolan-Halley, J., Alternative Dispute Resolution, West Publishing Company, Minnesota, 1991, pp. 223-226. El subrayado es mío.

41 State Justice Institute; op. cit., p. 42.

42 Ibid.

43 Recomendación N ${ }^{\circ}$ R (98)1 del Comité del Ministros de los Estados Miembros sobre Mediación Familiar (21 de enero de 1998). www.coe.int. Visitada el 9 de agosto de 2007. 
la década de los noventa en Estados Unidos, que difieren en la metodología empleada, pero que arrojan luces sobre el tema. Uno de ellos que indagó sobre el tratamiento de los casos y los niveles de acuerdo de una experiencia de Multi-Door Courthouse del estado de Massachusetts muestra que a los programas de mediación voluntaria ingresa un número inferior de casos que a los de mediación obligatoria, pero que los primeros muestran índices más altos de satisfacción y de acuerdos. ${ }^{44}$ El otro -sobre la base de encuestas enviadas por correo a los actores de procesos de mediación (partes, abogados y mediadores) - revela que el nivel de acuerdos no sufrió variaciones sustanciales según se trataba de mediación voluntaria u obligatoria ( $79 \%$ v/s $76 \%)$, lo que a juicio de los autores demuestra que la mediación es tan exitosa en uno como en otro caso. ${ }^{45}$

\section{LA MEDiaCión Obligatoria (O PREVIA) EN LOS TRIBUNALES DE FAMILIA. PROPUESTAS Y DESAFÍOS FUTUROS}

La nueva Justicia de Familia comenzó a operar en octubre de 2005 y hasta la fecha sólo se ha oído hablar de las dificultades por las que atraviesa. A pocos meses de su puesta en marcha ya se vaticinaba del colapso de los nuevos tribunales.

Muchas razones se han dado para explicar esta situación. Los primeros en dar la luz de alarma fueron los propios jueces de familia, señalando como principales problemas la subdotación de personal y la falta de mecanismos que permitan descongestionar el sistema, aludiendo, entre otras, la necesidad de establecer la derivación obligatoria a mediación. ${ }^{46}$

Por su parte, desde el Ejecutivo se ha sostenido que los errores de cálculo de la demanda -que a seis meses de funcionamiento ya doblaba las estimaciones iniciales- la introducción de la comparecencia personal y la voluntariedad de la mediación son las principales causas del colapso. ${ }^{47}$ Otros apuntan a problemas del diseño de los procedimientos, dificultades en la gestión interna de los tribunales y problemas del proceso de implementación de la reforma. ${ }^{48}$

En ese contexto, el Ejecutivo en julio de 2006 presentó un proyecto de reforma a la Ley de Tribunales de Familia en la que entre otros aspectos repone la figura de la

${ }^{44}$ National Center for State Courts/State Justice Institute; op. cit., pp. 103-105.

${ }^{45}$ Brett, J., Barsness, Z. y Goldberg, S., op. cit., p. 4.

46 "80 mil casos en sólo tres meses: Medidas por colapso en Justicia de Familia”, en El Mercurio, Santiago, 30 de diciembre de 2005; "Demanda colapsa a tribunales de familia”, en El Mercurio, Santiago, 28 de noviembre de 2005; "Jueza criticó duramente la implementación de los Tribunales de Familia”, en el Diario de Cooperativa, 17 de enero de 2006. www.cooperativa.cl. Página visitada el 24 de junio de 2006.

47 "El pariente pobre de la justicia”, entrevista al Ministro de Justicia, Sr. Isidro Solís, en La Tercera, Revista De Mujer a Mujer, Santiago, 25 de junio de 2006; "Por atochamientos: Abogados serán obligatorios en los juzgados de familia", en El Mercurio, Santiago, 23 de julio de 2006; "Ex ministro Bates subraya valor de la mediación obligatoria en las causas de familia”, en El Mercurio, Santiago, 25 de julio de 2006.

${ }^{48}$ Casas, L. et al. Informe sobre el funcionamiento de los tribunales de familia. Facultad de Derecho de la Universidad Diego Portales, Santiago, 2006. http://www.udp.cl/derecho/cij/publicaciones/InformeTribunalesdeFamiliaUDP_ Final_\%202\%201.pdf. Visitada 15 de abril de 2008. 
mediación obligatoria contenida en el proyecto de ley original. En síntesis, el texto aprobado establece la derivación obligatoria a mediación, previa a la interposición de la demanda en todos aquellos asuntos que versen sobre el derecho de alimentos, cuidado y crianza personal y régimen comunicacional. En estos casos, la mediación será gratuita para todos los usuarios. El Estado cubrirá los costos de los servicios a través del sistema de mediadores licitados, lo que implica un importante incremento del presupuesto del sistema de justicia de familia. En las demás materias -salvo las prohibidas, que se mantienen intactas- serán derivadas a mediación las partes que acepten la invitación del juez, quienes se harán cargo de los costos en proporciones iguales. Siempre será gratuita para quienes gocen del privilegio de pobreza, lo que significa que ya no será necesario obtener un informe favorable para acogerse al sistema. ${ }^{49}$

Aun cuando la introducción de la mediación obligatoria (o previa) se base exclusivamente en consideraciones de eficiencia y gestión de los recursos judiciales -descongestionar los saturados tribunales de familia- considero que ese enfoque no afecta los objetivos sustantivos del establecimiento de la mediación en el contexto familiar ni los principios que la sustentan.

Estimo que en el escenario actual chileno, donde priman el desconocimiento ${ }^{50}$ y el escepticismo respecto de la mediación, resulta adecuado propiciar la mediación anexa a los tribunales, tanto la obligatoria como la voluntaria, ya que puede "servir mejor a los intereses de las partes, del sistema y al público en general" ${ }^{51} \mathrm{y}$, de paso, contribuir a su legitimación social y cultural.

En efecto, la derivación a mediación por orden judicial puede resultar socialmente beneficiosa desde varios puntos de vista. Por una parte, no cabe duda que producirá un incremento de los casos, accediendo con ello a un número mayor de personas a las cuales se puede explicar el objetivo y naturaleza de este proceso.

Por otra parte, como indican los documentos revisados, estas personas pueden conocer un sistema de solución de controversias al cual en el futuro podrían acogerse en forma voluntaria o recomendar a otros. Esto se verifica con la opinión de usuarios derivados a mediación por el tribunal que optan por seguir el procedimiento y luego reconocen su utilidad. ${ }^{52}$ El desconocimiento, desinformación y prejuicios en torno a este proceso juegan en contra de su inserción.

Por lo demás, esta modalidad no es una novedad. Se aplica en diversas legislaciones comparadas ${ }^{53}$ y nuestro ordenamiento jurídico contempla la obligatoriedad de la

${ }^{49}$ Boletín 4349-18. Proyecto de ley que introduce modificaciones orgánicas y procedimentales a la Ley No 19.968, que crea los Tribunales de Familia. Ingresado a la Cámara de Diputados el 19 de julio de 2006.

${ }^{50}$ Todavía hay quienes creen que la mediación pretende la reconciliación de la pareja, creencia alimentada por normas legales confusas como las contenidas en la Ley de Matrimonio Civil. Para mayor información véase: Vargas, M., Casas, L., Azócar, M. J., op. cit., p. 27.

${ }^{51}$ State Justice Institute, op. cit., p. 42.

52 Vargas, M., Casas, L., Azócar, M.J., op. cit., p. 38.

53 Algunos ejemplos: Ley N 24.573 de Mediación y Conciliación del 27 de octubre de 2005 (Argentina); Ley No 8.858 de Mediación de la Provincia de Córdoba de 8 de junio de 2000; Ley N 5.487 de Mediación de la Provincia de Corrientes de 31 de octubre de 2000; Código Procesal Civil y Comercial de Entre Ríos 
mediación para los conflictos por daños en salud que regula la Ley N 19.966 de Garantías Explícitas en Salud. Incluso más, esta ley establece la mediación previa y obligatoria como un requisito de procesabilidad de la acción. ${ }^{54}$

En este sentido, en 1996 Carlos Peña señalaba la necesidad de decidir si la mediación habría de operar en el curso del proceso o como una alternativa a éste. Sostuvo que para el caso de los conflictos de familia "donde la calidad del bien público es mayor" 55 (en comparación al contencioso de masas) conviene adoptar la primera opción. Y finaliza diciendo que "dadas las características de la cultura jurídica en Chile, revestir todo el proceso de mediación de legitimidad jurídica". 56

Nada obsta, desde luego, que las partes puedan concurrir ante un mediador para resolver sus conflictos en forma extra o prejudicial, es decir, buscar una instancia de mediación voluntaria. Esta opción podría incentivarse eximiendo de la derivación obligatoria a quienes acrediten haber participado en un proceso sin éxito, ante un mediador registrado. Pero, reitero en una primera fase de instalación cultural de la mediación, las energías, tiempos y recursos deben dirigirse a la instauración de la mediación judicial o anexa a tribunales. Luego, una vez realizada una evaluación de la política pública -como sugiere el incrementalismo de Lindblom ${ }^{57}$ - y sobre la base de aproximaciones y comparaciones sucesivas, dar un nuevo paso encaminado a potenciar la mediación extrajudicial y voluntaria, la genuina mediación.

Con todo, la mediación anexa a tribunales impone ciertas exigencias. Parece indispensable satisfacer una serie de estándares mínimos en dos áreas especialmente sensibles para el desarrollo adecuado de la mediación y, que en la actualidad, no están suficientemente cauteladas. Me refiero a la calidad de la formación de los mediadores y a la calidad de los servicios prestados por éstos, cuestión -como vimos- que se sugiere considerar en las Normas Recomendadas por el State Justice Institute.

Se debe derribar la mayor cantidad posible de obstáculos que dificulten la utilización de la mediación, tanto en el ámbito judicial como fuera de él. Se hace necesario romper con las barreras que al interior de los tribunales cierran el paso a la mediación -principalmente la desinformación y el temor a los recortes de poder de jueces y funcionarios judiciales- mediante la oferta de capacitación y reuniones de trabajo y coordinación con los mediadores y autoridades sectoriales. Fuera de los tribunales, también es necesario hacerse cargo de las aprensiones y suspicacias que la mediación genera en el foro; no se ven razones que impidan incluir a los abogados litigantes en programas de capacitación

(Argentina); Ley N 9.776 de 12 de agosto de 2008; Rule 24.1 of the Rules of Civil Procedure de Ontario, Canadá; Mandatory Mediaton Act (CA Civil Code, Sec. 4607) de California, Estados Unidos.

${ }^{54}$ Ley 19.966 publicada en el Diario Oficial el 3 de septiembre de 2004. Si el prestador es un organismo privado, oficia de mediador la Superintendencia de Salud, mientras que si se trata de prestadores públicos, será el Consejo de Defensa del Estado quien ejercerá esta labor.

55 Op. cit., $\mathrm{N}^{\circ}$ 6. Peña, C., "Los sistemas alternativos de resolución de conflictos".

56 Ibid.

${ }^{57}$ Regonini, G., "El estudio de las políticas públicas”, en Documentación Administrativa, núm. 224-225, Instituto Nacional de Administración Pública, España, 1991, pp. 59-89. 
para que conozcan el escenario al cual van a enfrentarse. Todo lo anterior debe reforzarse con una maciza campaña de difusión que explique en forma clara y lenguaje sencillo tres puntos cruciales: qué es la mediación, cuál es su relación con el proceso y qué valor tienen los acuerdos.

Por otra parte, estimo necesario elevar los estándares para ser mediador familiar. Hoy cualquier profesional con un número de horas de capacitación y sin mayor experiencia profesional en el área puede inscribirse en el Registro de Mediadores del Ministerio de Justicia y prestar servicios de mediación familiar. ${ }^{58}$ El Estado debe ejercer un rol de garante de la formación de los mediadores para evitar este tipo de distorsiones y proveer los mecanismos que aseguren una eficiente implementación de la mediación. Estimo que algunas alternativas para ello pueden ser exigir a los organismos de formación de mediadores que se acrediten ante el Ministerio de Justicia o, en su defecto, permitir sólo la inscripción de mediadores formados en instituciones de educación superior acreditadas ante el Ministerio de Educación (CNA). Junto con lo anterior, deben elevarse los requisitos para ser inscritos en el Registro Único de Mediadores, por ejemplo, exigiendo a los postulantes la rendición de un examen habilitante. Además sería deseable requerir a los mediadores inscritos que quieran permanecer en el Registro acreditar formación continua.

Considero que tomando estos resguardos y propiciando un debate serio en torno a la mediación familiar es posible acercarse progresivamente a los objetivos de políticas públicas planteados, respecto de los cuales no parece haber discusión.

\section{CONClusiones}

El establecimiento de mecanismos alternativos de resolución de conflictos en el sistema de justicia de familia responde a un triple objetivo de política pública. Por una parte, buscan mejorar el acceso al sistema judicial, ofrecer respuestas más adecuadas de acuerdo a la especial naturaleza de cierto tipo de conflictos y, por otra, persiguen mejorar la gestión de los tribunales contribuyendo a su descarga.

En ese contexto, la mediación constituye uno de los pilares de la reforma a la justicia familiar, pues ofrece a las partes un espacio de colaboración para la construcción de consensos, principalmente en los casos de conflictos por la ruptura de la pareja. Permite restablecer los canales de comunicación que se han empantanado ${ }^{59}$ y asociar a las partes en la búsqueda de soluciones mutuamente satisfactorias, considerando siempre los intereses y derechos de los niños, niñas y adolescentes.

La regulación legal vigente establece un sistema de mediación judicial que surge como resultado de la aceptación de las partes de la propuesta del juez, el que habitualmente

${ }^{58}$ Se exige a los mediadores acreditar 180 horas de formación teórico-práctica y 40 horas de práctica supervisada o pasantía Artículo 4. Decreto Supremo N 957. Aprueba Normas Reglamentarias Necesarias para la Ejecución de la Ley No 19.968. Santiago, 22 de noviembre de 2004.

59 Suares, M., op. cit., p. 29. 
se conoce como mediación voluntaria. Este sistema ha mostrado ser ineficiente para los objetivos de políticas planteados, en especial para la descongestión del despacho judicial. Por ello y por otras razones que explican el colapso de los tribunales de familia, el Congreso Nacional aprobó una reforma que establece la mediación previa obligatoria.

Sin embargo, doctrinariamente tanto si la derivación nace por orden o por sugerencia del juez, se trata de una mediación obligatoria o involuntaria. Razón por la cual, más que atender a los argumentos que justificarían la derivación obligatoria a mediación, es necesario preguntarse cómo hacer más eficiente y eficaz la mediación judicial o anexa a tribunales en función de los propósitos deseados.

Existen buenas razones para mantener y fortalecer la mediación anexa a tribunales, al menos en una primera fase de legitimación cultural y jurídica de este mecanismo. Ello porque permite aumentar el volumen de casos derivados y "presentar" la mediación a las partes y sus abogados, quienes podrían hacer uso de ella en el futuro. Además la escasa evidencia empírica muestra resultados disímiles, por lo que no es posible concluir a ciencia cierta que la mediación obligatoria signifique menores niveles de acuerdo, no así respecto de la satisfacción de los usuarios.

Desde una perspectiva de políticas públicas, entonces, parece viable y aconsejable tomar medidas para afianzar la mediación familiar anexa a tribunales, en cualquiera de sus modalidades, y una vez que se haya instalado culturalmente comenzar a delinear cursos de acción destinados a promover e incentivar la mediación voluntaria fuera del contexto judicial.

\section{BIBLIOGRAFÍA}

Alliende, L. y otros, El proceso de mediación, Editorial Jurídica de Chile, Santiago, 2002.

Barona, S., La solución extrajudicial de conflictos. ADR y Derecho Procesal. Tirant lo Blanch. Valencia; 1999.

Bernal, T., La mediación: una solución a los conflictos de ruptura de pareja, Ed. Colex, Madrid, 1998.

BRAZIL, W. Y WILSON, W., "The arguments for and against mandatory arbitration", en FJC Directions. Federal Judicial Center, No 7, Washington. 1999.

Brett, J., Barsness, Z. y Goldberg, S., "La eficacia de la mediación. Un análisis independiente de casos gestionados por cuatro importantes proveedores de servicio", en Burs, M.I. (coord.), Suplemento de Resolución de Conflictos (R.C.), La Ley, Buenos Aires, 1997.

CÁrdenas, E., La mediación en conflictos familiares, Editorial Lumen/Humanitas, Buenos Aires, 1998.

CASAs, L. et al., Informe sobre el funcionamiento de los tribunales de familia. Facultad de Derecho de la Universidad Diego Portales, Santiago, 2006.

Cillero, M., "El interés superior del niño en el marco de la Convención Internacional de los Derechos del Niño", en García, E. (compilador), en Infancia, Ley y Democracia en América Latina. Temis, Bogotá, 1999.

Colombo, J., La jurisdicción, el acto jurídico procesal y la cosa juzgada en el derecho chileno, Editorial Jurídica de Chile, Santiago, 1980.

Correa, P., "Los niños en la mediación familiar. Comentarios al artículo de Macarena Vargas", en Revista de Derechos del Niño, Facultad de Derecho Universidad Diego Portales, núm. 1, 2002. 
Couso, J., "El niño como sujeto de derechos y la nueva Justicia de Familia. Interés Superior del Niño, Autonomía progresiva y derecho a ser oído", en Academia Judicial de Chile. Derecho de Familia e Infancia, Santiago, 2005.

- “ "Más acá del Interés Superior del Niño”, en García, E. (compilador), Infancia, Ley y Democracia en América Latina. La cuestión de la responsabilidad penal de los adolescentes, Ediciones del Signo, Buenos Aires, 2004.

DAvis, W., "Diseño de sistemas para resolver conflictos: La experiencia con multipuertas en Estados Unidos”, en Gottheil, J. y Schiffrin, A., Mediación. Una transformación en la cultura, Editorial Paidós, Buenos Aires, 1996.

Gómez, P., "Propuestas y reflexiones éticas acerca del ejercicio de la mediación en Chile como forma de resolución no adversarial de los conflictos", en Revista de Derecho de la Universidad Católica de Valparaíso, Valparaíso, 1999.

Haynes, J., Fundamentos de la Mediación Familiar, Gaia Ediciones, Barcelona, 1993.

Moore, C., El proceso de mediación. Métodos prácticos para la resolución de conflictos, Editorial Granica, Buenos Aires, 1995.

PeÑA, C., "Los sistemas alternativos de resolución de conflictos", en Revista de Estudios Sociales, núm. 88, Corporación de Promoción Universitaria (CPU), Santiago, 1996.

Pereira, H., La cosa juzgada en el proceso civil, Editorial Jurídica ConoSur Ltda., Santiago, 1997.

Regonini, G., "El estudio de las políticas públicas", en Documentación Administrativa, núm. 224225, Instituto Nacional de Administración Pública, España, 1991.

SAnder, F., "Varieties of Dispute Processing. National Conference on the Dissatisfaction with de Administration of Justice", en Federal Rules Decisions, West Publishing CO, vol. 70, num. 1, Minnesota, 1976.

Singer, L., Resolución de conflictos. Técnicas de actuación en los ámbitos empresarial, familiar y legal. Editorial Paidós, Barcelona, 1996.

SIX, J. F., Dinámica de la mediación, Editorial Paidós, Barcelona, 1997.

Suares, M., Mediando en sistemas familiares, Editorial Paidós, Buenos Aires, 2002.

Turner, S., "Los Tribunales de Familia", en Revista Ius et Praxis, vol. 8, № 2, Talca, 2002.

VARGas, J. E., "Problemas de los sistemas alternos de resolución de conflictos como alternativa de política pública en el sector judicial”, en Revista Sistemas Judiciales, Centro de Estudios de Justicia de las Américas (CEJA), núm. 2, 2002.

Vargas, M. (ed.), Mediación Familiar. Sistematización de una experiencia, Ministerio de Justicia de Chile, Santiago, 2000.

Vargas, M., Casas, L., Azócar, M. J., Mediación Familiar y Género, Cuaderno de Análisis Jurídico, núm. 18. Serie Publicaciones Especiales, Facultad de Derecho, Universidad Diego Portales, Santiago, 2008.

Textos legales

Boletín 4349-18. Proyecto de ley que introduce modificaciones orgánicas y procedimentales a la Ley No 19.968, que crea los Tribunales de Familia. Ingresado a la Cámara de Diputados el 19 de julio de 2006.

Cámara de Diputados. Oficio No 7517 de 12 de junio de 2008.

Decreto Supremo No 957. Aprueba Normas Reglamentarias Necesarias para la Ejecución de la Ley $\mathrm{N}^{\circ}$ 19.968. Santiago, 22 de noviembre de 2004.

Informe de las Comisiones Unidas de Constitución, Legislación y Justicia y de Familia recaído en el Proyecto de Ley que crea los Juzgados de Familia. Boletín No 2118-18. 
Ley $\mathrm{N}^{\circ} 19.966$ sobre Garantías Explícitas en Salud publicada en el Diario Oficial el 3 de septiembre de 2004.

Ley $\mathrm{N}^{\circ} 19.968$ que crea los Tribunales de Familia publicada en el Diario Oficial el 30 de agosto de 2004.

Mensaje del Presidente de la República al Proyecto de Ley que crea los Tribunales de Familia, Boletín No 2118-18. Noviembre de 1997.

Segundo Informe de la Comisión de Constitución, Legislación y Justicia del Senado recaído en el Proyecto de Ley que crea los Juzgados de Familia. Boletín No 2.118-18 Valparaíso, 9 de julio de 2003.

Informes y documentos

Facultad de Derecho de la Universidad Diego Portales y Centro de Estudio de Justicia de las Américas (CEJA). Informe Final Estudio "Diseño de un Modelo de Licitación Pública de Servicios de Mediación. Santiago, 2008.

Facultad de Ciencias Económicas y Administrativas (FACEA), Universidad de Concepción, Estudio sobre la calidad de los servicios licitados de mediación del Ministerio de Justicia, Concepción, 2006.

Ministerio de Justicia, Informe de la Subcomisión sobre Mediación de la Comisión de Reforma de la Ley de Tribunales de Familia, documento inédito, Santiago, 2006.

National Center of State Courts and State Justice Institute, National Symposium on Court-connected Dispute Resolution Research. A Report on Current Research Findings-Implications for Courts and Futures Research Needs, 1994.

Pontificia Universidad Católica de Valparaíso, Centro de Estudios de Asistencia Legislativa (CEAL), Informe final Estudio "Impacto de la reforma a la Ley $N^{\circ} 19.968$ en la demanda de ingresos de los Tribunales de Familia y el Sistema Nacional de Mediación", vol. 1, Valparaíso, 2007.

State Justice Institute (SJI), Normas recomendadas para programas de mediación anexos a los tribunales. Traducción al castellano realizada por la Fundación Libra de Argentina. Buenos Aires, 1993.

Report $\mathrm{N}^{\circ} 1$ of the Law and Public Policy Committee of the Society of Professionals in Dispute Resolution (SPIDR), "Mandated participation and settlement coercion: dispute resolution as it relates to the courts", en Nolan-Halley, J., Alternative Dispute Resolution, West Publishing Company, Minnesota, 1991.

Notas de prensa

"80 mil casos en sólo tres meses: Medidas por colapso en Justicia de Familia", en El Mercurio, Santiago, 30 de diciembre de 2005.

"Demanda colapsa a tribunales de familia", en El Mercurio, Santiago, 28 de noviembre de 2005.

“Jueza criticó duramente la implementación de los Tribunales de Familia”, en el Diario de Cooperativa, 17 de enero de 2006.

"El pariente pobre de la justicia”, entrevista al Ministro de Justicia, Sr. Isidro Solís, en La Tercera, Revista De Mujer a Mujer, Santiago, 25 de junio de 2006.

"Por atochamientos: Abogados serán obligatorios en los juzgados de familia", en El Mercurio, Santiago, 23 de julio de 2006.

"Ex ministro Bates subraya valor de la mediación obligatoria en las causas de familia", en El Mercurio, Santiago, 25 de julio de 2006. 